SALUD

Ciencias sociales

HUMANIDADES

LA NEUROÉTICA Y LA POSIBILIDAD DE LA MEJORA HUMANA

PENSAMENT ACTUAL

SILENCIO EN EL RUIDO: OPORTUNIDADES PARA LA MEDITACIÓN EN LA VIDA COTIDIANA -SALVADOR CASADO

ARTE, SALUD Y SOCIEDAD

UN ENCARGO SOBRE PLA-NARBONA

-MARIA LEON SANROMȦ 


\section{Co-directores}

Marc Antoni Broggi i Trias (PCBC)

Francesc Borrell (UB)

Jefa de Redacción

Núria Estrach (UAB)

\section{Consejo científico}

Juan Carlos Hernández Clemente

Juan Medrano Albéniz

Vicente Morales Hidalgo

\section{Correspondencia}

Web:

http://www.fundacionletamendi.com

Correo electrónico:

info@fundacionletamendi.com

Envío de manuscritos:

http://www.fundacionletamendi.com/revista-foliahumanistica/envio-de-manuscritos/

\section{Información editorial}

Folia Humanística publica artículos por encargo solicitados a especialistas, así como aquellas propuestas enviadas por los autores y aceptadas tras su evaluación por pares de académicos especializados.

Los textos recibidos se publicaran en la lengua original (castellano, catalán, inglés y francés); los que se consideren de relevancia mayor serán traducidos al inglés y castellano.

Los artículos deben ser originales y acompañados del documento "derechos de autor" que encontrarán en la web, junto a las normas de presentación a seguir.

Cada artículo publicado al final tendrá especificado la referencia de citación, donde se incluirá el número DOI ${ }^{\circledR}$.

\section{Distribución}

La Revista Folia Humanística es de libre acceso a consultar online.

http://www.fundacionletamendi.com/category/rev istal

Folia Humanística es una revista internacional que tiene el doble objetivo de fomentar, por un lado, la reflexión y el debate público en el ámbito de la Salud, Ciencias Sociales y Humanidades, y por el otro, la colaboración entre distintos equipos de investigación nacionales e internacionales que dinamicen el diálogo entre la filosofía de la medicina, la salud pública y la justicia social. Dividida en "Tema del día", (artículos para el debate), "Pensamiento actual", (artículos críticos de novedades editoriales), y "Arte, Salud y Sociedad", la revista se esfuerza en fortalecer las conexiones entre la investigación académica, la práctica clínica, las experiencias de los pacientes y sus implicaciones éticas y estéticas en la sociedad. Todo ello con la intención de favorecer la reflexión entre diferentes disciplinas sobre temas de actualidad y las tendencias más novedosas en el campo de las Humanidades y la Salud.

Folia Humanística is an International Journal, born with the dual aim of fuelling the discussion and public debate on issues of health, social sciences and humanities and on the hand, of fostering cooperation between various research groups, both national and International, to spur the dialogue between philosophy and medicine, public health and social justice. The Journal is divided into three different sections: "main focus" (article for debate), "Contemporary thought" (critical reviews of new Publications) and "Arts, Health and Society" which all contribute to strengthening the links between academic research, clinical practice, the experience of patients and their ethical and esthetical implications for society. Ultimately, the intention of the Journal is to promote reflection at the crossroads of several disciplines on topical issues and new trends in humanities and health. 


\title{
NO ES UN JUEVES CUALQUIERA
}

\section{Beatriz Ogando Díaz}

\begin{abstract}
Resumen: Basada en hechos y circunstancias reales, esta es una reflexión sobre los modos de morir en la actualidad en la sociedad occidental en el contexto de la aprobación de una de las llamadas "leyes para morir con dignidad" en el entorno español
\end{abstract}

Palabras clave: autonomia/ eutanasia/ muerte digna/ cuidados paliativos/.

Abstract: THIS ISN'T A NORMAL THUSDAY

Based on real facts and circumstances, this is a reflection on the ways of dying currently in Western society in the context of the approval of one of the so-called "die with dignity laws" in Spain.

Keywords: autonomy/ euthanasia/ death with dignity/ palliative care

Artículo recibido: 14 enero 2018; aceptado: 30 marzo 2018.

1

No es un jueves cualquiera. En la cafetería de la Asamblea de Madrid resuenan las palmadas en la espalda y se regalan sonrisas y felicitaciones. Satisfacción general de los diputados que celebran la inusual unanimidad en un tema tan espinoso. El hashtag \#muertedigna empezó a ser trending topic nada más aprobarse la ley que pretende conseguir que la muerte de los madrileños sea dulce y apacible.

No es un jueves cualquiera. Javier ha podido dormir tranquilo, por fin, esta noche. Recostado en la cama, acaricia su muñón con impaciencia. Su mujer le recuerda que la médica no vendrá antes de las dos.

—Tómate el Zaldiar y descansa un poco.

—Déjame en paz. Esa pastilla me aturde y quiero estar bien despierto.

La mujer se escabulle hasta la cocina para evitar su mal humor. Javier se queda en la cama resoplando y rumiando sus dudas. Se agita, recordando aquellos latidos incontrolables, la angustia en el pecho, esa falta de aire insufrible. No, así no, se dice. Mira al reloj, sabe que su tiempo se acaba. Estira la sábana e intenta leer, pero no consigue concentrarse. 
No es un jueves cualquiera. Faltan dos compañeros y la consulta de Isabel se ha llenado de pacientes "sin cita"; urgencias poco urgentes, historias desordenadas. A mitad de la mañana recibe una llamada: es la mujer de Javier, no es nada urgente, pero Javier quiere que vaya a su casa para hablar con ella. Isabel siente la tentación de dejarlo para mañana, pero piensa que es mejor no demorarlo a un viernes. Supone lo que Javier le va a pedir y se permite sentir una inmensa pereza. Intenta acelerar la atención de las visitas de la consulta pero cada persona necesita su tiempo y no puede condensar angustias, miedos y síntomas mal definidos. Poco más tarde de las dos coge su maletín, cierra la consulta y se marcha. De camino a la casa de Javier mira el móvil. En twitter lee que han aprobado la ley de muerte digna, no puede reprimir una sonrisa sarcástica. Los comentarios de los periodistas que no distinguen los cuidados paliativos de la sedación ni de la eutanasia le ponen de los nervios. Toda esa palabrería legalista no añade nada a lo ya escrito desde hace años. Rápidamente envía la noticia a sus compañeros del grupo de bioética, con un par de emoticonos que pretenden evidenciar su frustración. Sube a casa de Javier y la mujer le lleva directamente a la habitación.

—Siéntese, doctora —dice Javier con ese modo suyo de pedir las cosas imponiéndolas.

— ¿Qué tal está, Javier? —dice Isabel mientras le estrecha la mano.

—Vamos al grano —dispara Javier mientras la doctora se sienta a su lado—. Yo lo que quiero es la eutanasia. Y si no puede ser, que me seden. No estoy dispuesto a volver a pasar por aquello.

Isabel se acomoda en la silla, admitiendo el disparo que le da de pleno. Recorre la habitación con la vista y se para un momento en la pierna ortopédica apoyada en la mesilla. Un vaso de agua, la caja de analgésicos, un paquete de pañuelos. Respira y procura encontrar el tono adecuado.

- Le entiendo perfectamente, Javier, porque sé el sufrimiento por el que ha pasado, y el que le queda por delante. Créame que me gustaría responder a su petición y ayudarle. Pero ni siquiera hoy, que en la Asamblea de Madrid han firmado una ley que llaman de muerte digna, va a ser posible cumplir su primer deseo. Créame, lo siento — responde mirando directamente a los ojos de Javier. 
- Lo suponía. No tengo ningún miedo a la muerte. Estoy seguro de que lo mejor sería terminar hoy mismo pero, si eso no es posible, doctora quiero que me seden para no pasar otra vez por ese martirio.

\section{2}

—¿Está seguro, Javier, de que hemos llegado al final?

- Hace tiempo ya que he llegado al final. Incluso antes de que el cáncer diera la cara. No quiero más trasfusiones, ya lo sabe. Pero no quiero morir con el corazón al galope y ese ahogo insoportable.

— ¿Lo ha hablado con su familia? - dice Isabel mientras gira la cabeza buscando a la mujer que está discretamente en el quicio de la puerta.

-Este asunto lo decido yo. No hay nada que hablar con nadie.

—¿Algo que resolver, algún asunto pendiente, alguien de quien despedirse?

-Todo está cerrado. Cuanto antes termine todo, mejor.

Isabel repasa ahora los síntomas, los tratamientos que Javier tiene disponibles, anticipa las posibles complicaciones. Sugiere soluciones, al menos para paliar lo que pueda aparecer.

Javier la escucha asintiendo en silencio. Se despide de la mujer en la cocina, mientras ella fuma un poco nerviosa un cigarrillo. Comparten con complicidad el difícil carácter de Javier y su mala disposición para ser cuidado. Ella espera que todo acabe pronto, está visiblemente agotada. Isabel se despide de Javier desde la puerta. Mañana empezará el final. Son más de las tres y media y está cansada, pero Isabel decide volver a la consulta para poner la muerte en marcha. Una marcha lenta, mucho más lenta que los deseos de Javier.

No es un jueves cualquiera. Ha pasado una semana de infusores, ampollas de morfina, agujas por debajo de la piel. Una caja de gasas que refrescan los labios y otra de pañuelos húmedos de mocos y lágrimas. Siete días de estertores y despertares, taquicardias y alguna pausa de apnea que no fue la definitiva. 168 horas de familiares y profesionales entrando y saliendo en silencio de la habitación de Javier, sin curas ni notarios. Una semana, siete días, 168 horas después de que lo pidiera directo y sin rodeos, Javier muere. Mientras Isabel rellena el certificado de 
FOLIA HUMANÍSTICA, Revista de Salud, ciencias sociales y humanidades No 9, junio-julio 2018.ISSN 2462-2753

No es un jueves cualquiera

Beatriz Ogando Díaz

defunción y siente el peso de todo ese tiempo inútil, en twitter continúa circulando el hashtag \#muertedigna.

\section{Beatriz Ogando Díaz}

Doctora en Medicina. Especialista en medicina de familiar y comunitaria. Magister en cuidados paliativos y bioética.

Centro de Salud Casa de Campo. SALUDMADRID

Madrid

E-mail: beatriz.ogando@salud.madrid.org

\section{Cómo citar este artículo:}

Ogando Díaz, B., "No es un jueves cualquiera", en Folia Humanística, 2018; 9: 56-59. Doi: http://dox.doi.org/10.30860/0041.

(c) 2018 Todos los derechos reservados a la Revista Folia Humanística de la Fundación Letamendi Forns. This is an open access article. 